\title{
Synthetic Cannabinoid Receptor Agonist-related Intoxication: Impact and Legislative Success
}

\author{
Getaw Worku Hassen ${ }^{1, *}$, Andrew Eng ${ }^{2}$, Ioana Scherbakova ${ }^{3}$, Aida Eliza Abdul Majid ${ }^{3}$, \\ Alessandra Renee Piscina ${ }^{3}$, Thara Amilineni ${ }^{2}$, Cynthia Francois ${ }^{2}$, Asha Roy ${ }^{1}$, Kevin Yiu ${ }^{1}$, \\ Canny Li $^{1}$, Michael Lyashenko ${ }^{1}$, Monica Diep ${ }^{1}$, Roger Chirurgi ${ }^{1}$, Golnar Pashmforoosh ${ }^{1}$, \\ Hossein Kalantari ${ }^{1}$
}

\author{
${ }^{1}$ Department of Emergency Medicine, Metropolitan Hospital Center, NYMC, New York, USA \\ ${ }^{2}$ School of Medicine, New York Medical College, Valhalla, USA \\ ${ }^{3}$ Premedical Postbaccalaureate Program, Columbia University, New York, USA
}

Email address:

getawworku.hassen@nychhc.org (G. W. Hassen)

*Corresponding author

\section{To cite this article:}

Getaw Worku Hassen, Andrew Eng, Ioana Scherbakova, Aida Eliza Abdul Majid, Alessandra Renee Piscinal, Thara Amilineni, Cynthia Francois, Asha Roy, Kevin Yiu, Canny Li, Michael Lyashenko, Monica Diep, Roger Chirurgi, Golnar Pashmforoosh, Hossein Kalantari. Synthetic Cannabinoid Receptor Agonist-related Intoxication: Impact and Legislative Success. American Journal of Internal Medicine. Vol. 8, No. 1, 2020, pp. 30-33. doi: 10.11648/j.ajim.20200801.16

Received: December 19, 2019; Accepted: January 16, 2020; Published: January 31, 2020

\begin{abstract}
Synthetic cannabinoids Receptor Agonist (SCRA) intoxication presents with various medical and psychiatric symptoms. The products are sold as K2 or Spice. The symptoms range from agitation, altered mental status (AMS), lethargy, paranoid behavior, psychosis and seizures. In some cases, brief psychiatric or inpatient medicine admission was required for stabilization. Some patients seem to stay longer for observation in the ED. These patients worsen the already problematic ED crowding. To assess K2-related ED presentation, length of stay in the ED and types of disposition over a 5 year period. A retrospective chart review of patients who presented with K2 intoxication. Charts were reviewed from January 1, 2012 until December 31 ${ }^{\text {st }}$, 2016 excluding 2016. Demographics, age, gender, past psychiatric illness and other substance abuse history were reviewed. A total of 1405 patients were seen for K2-related ED visits from January 1, 2012 until December $31^{\text {st }}, 2016$ of which 1279 patients (91\%) were male and 126 patients (9\%) were female. One hundred thirty nine patients (9.9\%) were hospitalized and 1266 patients (90.1\%) were either discharged or left from the ED. Twenty-eight (2.0\%) stayed more than 16 hours in the ED. Of the 53 patients, whose urine the showed benzodiazepine or opiates 36 patients stayed more than 6 hours in the ED. Most patients with K2 use were male (91\%) between the ages of 19 and 50 years (76.4\%). There was a surge in K2related presentation in 2015, particularly in the months of April until November. In addition, K2-related intoxication led to prolonged ED stay, which could affect the ED crowding phenomenon. A concerted effort from public pressure and legislative measures led to a reduction of K2-related visits to the ED.
\end{abstract}

Keywords: SCRAs, Intoxication, ED Crowding, Length of Stay

\section{Introduction}

Synthetic cannabinoids Receptor Agonist (SCRA) intoxication presents with various medical and psychiatric symptoms. The symptoms of intoxication range from agitation, altered mental status (AMS), lethargy, paranoid behavior, psychosis and seizures [1-11]. These products, commonly known as K2 or Spice, come in different flavors with different compounds. Common herbal plants are sprayed with chemical compounds that act of cannabinoid receptors (CBs) and are legally marketed as incense and potpourri [12]. It is believed that some of the herbal products have intrinsic psychotropic effects, and the combination produces different clinical and psychiatric symptoms even if they are sold as harmless agents [12, 13]. Our Emergency Department (ED) has experienced an increasing number of 
young patients that have used K2 and present with different clinical symptom including violent behavior, sometimes requiring sedation [14-18]. In some cases, brief psychiatric or inpatient medicine admission was necessary for stabilization. Some patients seem to stay longer for observation in the ED leading to ED crowding, a well-known problem [16, 19, 20]. In other hospitals bleeding complications from use of SCRA that was laced with rat poison have been reported [21].

Given the fact that ED crowding affects patient flow, patient care and possibly mortality as reported in the literature, we aim to study the effects of K2-related ED presentation, length of stay in the ED and types of disposition over a 5 year period. Our hospital has seen a significant number of K2-related patients that came and stayed in the ED for an extended period, requiring at times sedation and monitoring. Some of them had to be admitted to the department of internal medicine or psychiatry. These patients may have severe intoxication. When they present with complications such as status epilepticus and hypotension, this utilizes many resources in the ED and can overwhelm its capacity, leading to overcrowding and compromised care.

\section{Material and Methods}

A retrospective chart review of patients who presented with K2 intoxication. Charts were reviewed from January 1, 2012 until December 31 ${ }^{\text {st }}, 2016$ excluding 2016. Demographics, age, gender, past psychiatric illness and other substance abuse history were reviewed. We used our daily census list to select patients by chief complaint that included K2. Descriptive statistic was performed. A waiver to review charts was granted by the Institutional Review Board (IRB).

\section{Results}

A total of 1405 patients were seen for K2-related ED visits from January 1, 2012 until December 31 $1^{\text {st }}, 2016$ of which 1279 patients (91\%) were male and 126 patients (9\%) were female. One hundred thirty nine patients (9.9\%) were hospitalized and 1266 patients (90.1\%) were either discharged or left from the ED. Seven hundred sixty eight (54.7\%) stayed in the ED between 4-16 hours. Twenty-eight (2.0\%) stayed more than 16 hours in the ED. Six hundred and eight patients (43.3\%) stayed less than 4 hours in the ED. Of the 53 patients, whose urine the showed benzodiazepine or opiates 36 patients stayed more than 6 hours in the ED. It is not clear whether the benzodiazepines were given in the ED or whether the patients took it. Table 1 summarizes the demographics and clinical data.

Tables Demographics and Clinical Data.

Table 1. Distribution of visits by month and year.

\begin{tabular}{|c|c|c|c|c|c|c|c|c|c|c|c|c|c|}
\hline & Jan & Feb & Mar & Apr & May & Jun & Jul & Aug & Sep & Oct & Nov & Dec & Total \\
\hline 2012 & 2 & 0 & 0 & 3 & 0 & 1 & 0 & 1 & 2 & 2 & 0 & 1 & 12 \\
\hline 2013 & 1 & 1 & 0 & 1 & 2 & 4 & 5 & 6 & 6 & 6 & 10 & 6 & 48 \\
\hline 2014 & 8 & 6 & 11 & 5 & 12 & 14 & 17 & 34 & 57 & 52 & 43 & 21 & 280 \\
\hline 2015 & 24 & 18 & 23 & 130 & 94 & 93 & 121 & 129 & 97 & 74 & 59 & 24 & 886 \\
\hline 2016 & 1 & 15 & 14 & 43 & 5 & 5 & 19 & 16 & 14 & 10 & 11 & 26 & 179 \\
\hline
\end{tabular}

Table 2. Distribution by age and gender.

\begin{tabular}{llll}
\hline & M & F & Total \\
\hline Age 18 or under & 4 & 4 & 8 \\
$19-50$ & 975 & 98 & 1073 \\
Age $>50$ & 300 & 24 & 324 \\
Total & 1279 & 126 & 1405 \\
\hline
\end{tabular}

Table 3. Disposition types.

\begin{tabular}{ll}
\hline Disposition & Number of Patients \\
\hline Hospitalized & 139 \\
ED visit only & 1266 \\
\hline
\end{tabular}

Table 4. Length of stay by hours.

\begin{tabular}{ll}
\hline Length of Stay (Hours) & Number of Patients \\
\hline$<4$ & 608 \\
$4-12$ & 711 \\
$12-24$ & 84 \\
$>24$ & 2 \\
\hline
\end{tabular}

\section{Discussion}

Substance abuse including synthetic drugs has gained national interest due to the increased ED visits and associated mortality. K2 or Spice is one of the synthetic drugs used by young individuals. It became popular due to intense high and cheaper cost and easy online accessibility [22]. Despite being sold as harmless incenses, K2 had several side effects such as sedation, hypotension, bradycardia, rhabdomyolysis, renal failure and seizure [1, 15, 17, 18, 23]. Anecdotal cases of stroke, myocardial infarction (MI) and death have been reported [1, 2, 7, 24, 25]. Initial evaluation of a patient with K2-intoxication and altered mental status (AMS) is directed towards making sure that there are no life threatening injuries. Following the initial evaluation, based on the vital signs and general appearance, patients are observed and reassessed. Some may require hospital admission. The observation time varies depending on patients' level of consciousness and/or vital signs. Patients who have abnormal vital signs and AMS require monitoring devices and longer observation time including hospital admission. In addition, some of these patients are aggressive and agitated requiring sedation to prevent self-harm and harm to hospital employees, which further prolonged their ED stay due to additive/synergistic sedative effects of $\mathrm{K} 2$ and medications. Moreover, some abuse several other recreational drugs or prescription opioids at the same time that may affect their level of consciousness. These factors contribute to the wellrecognized problem of ED overcrowding that can impacts 
patient care and outcome. It was reported that ED overcrowding contributes or increased mortality [16, 26]. Our emergency room encountered a wave of intoxicated young adults from recreational drugs such as Molly, Ecstasy and Phencyclidine (PCP) during the famous annual Electric Zoo festival in New York City [27]. The festival occurs in close proximity to our ED. Starting 2012 we started seeing patients who present with $\mathrm{K} 2$ intoxication occasionally, but from 2014 onward, we have seen 20-30 patients during a 24 $\mathrm{h}$ shift until it started to decline. When several people overdoses in different areas law enforcement officials made an effort to curb the sale of $\mathrm{K} 2$ and raided the stores suspected of selling K2 [19, 20, 28, 29]. The decline in K2 intoxication coincided with the law enforcement action that led to raiding stores [28]. These measures led to a dramatic decrease in patients with K2 intoxication. Even though few individuals come to the ED with $\mathrm{K} 2$ intoxication, the high volume visits decreased. The results of this study are summarized in Tables 1-4).

The results of this study are limited by some factors. Our search was based on the chief complaint that included K2. Patients who were triaged with other chief complaints despite the use of K2 and K2-related symptoms will be missed. The patients K2 use is self-reported or reported by EMS, family members or friends. No test was performed to confirm the presence of components of SCRA in bodily fluids. Prolonged stay in the ED can have several factors such as medical restrains/ sedation and could not be solely attributed to the intoxication from $\mathrm{K} 2$.

\section{Conclusions}

Most patients with K2 use were male (91\%) between the ages of 19 and 50 years (76.4\%). There was a surge in K2related presentation in 2015, particularly in the months of April until November. In addition, K2-related intoxication led to prolonged ED stay, which could affect the ED crowding phenomenon. A concerted effort from public pressure and legislative measures led to a reduction of K2related visits to the ED.

Conclusively, substance abuse is a growing public health crisis and it requires educating and engaging the community. In addition, early involvement of law enforcement is of paramount importance as they can investigate and arrest the sources of distribution. Our institution holds information sessions with community leaders and law enforcement personnel to effectively educate the community and combat this public health problem. The next step may be to overcome the lag in changes in government policies, as manufacturers are constantly changing chemical compositions to avoid legislative restrictions.

\section{References}

[1] Alipour, A., et al., Review of the many faces of synthetic cannabinoid toxicities. Ment Health Clin, 2019. 9 (2): p. 9399.
[2] Argamany, J. R., K. R. Reveles, and B. Duhon, Synthetic cannabinoid hyperemesis resulting in rhabdomyolysis and acute renal failure. Am J Emerg Med, 2016. 34 (4): p. 765 e1-2.

[3] Bernson-Leung, M. E., L. Y. Leung, and S. Kumar, Synthetic cannabis and acute ischemic stroke. J Stroke Cerebrovasc Dis, 2014. 23 (5): p. 1239-41.

[4] Buser, G. L., et al., Acute kidney injury associated with smoking synthetic cannabinoid. Clin Toxicol (Phila), 2014. 52 (7): p. 664-73.

[5] Castaneto, M. S., et al., Synthetic cannabinoids: epidemiology, pharmacodynamics, and clinical implications. Drug Alcohol Depend, 2014. 144: p. 12-41.

[6] Lapoint, J., et al., Severe toxicity following synthetic cannabinoid ingestion. Clin Toxicol (Phila), 2011. 49 (8): p. 760-4.

[7] Mir, A., et al., Myocardial infarction associated with use of the synthetic cannabinoid K2. Pediatrics, 2011. 128 (6): p. e1622-7.

[8] Schneir, A. B. and T. Baumbacher, Convulsions associated with the use of a synthetic cannabinoid product. J Med Toxicol, 2012. 8 (1): p. 62-4.

[9] Tai, S. and W. E. Fantegrossi, Synthetic Cannabinoids: Pharmacology, Behavioral Effects, and Abuse Potential. Curr Addict Rep, 2014. 1 (2): p. 129-136.

[10] van Amsterdam, J., T. Brunt, and W. van den Brink, The adverse health effects of synthetic cannabinoids with emphasis on psychosis-like effects. J Psychopharmacol, 2015. 29 (3): p. 254-63.

[11] Waugh, J., et al., Epidemiology and clinical features of toxicity following recreational use of synthetic cannabinoid receptor agonists: a report from the United Kingdom National Poisons Information Service. Clin Toxicol (Phila), 2016. 54 (6): p. 512-8.

[12] Hassen, G. W., et al., Analysis of K2 products sold as incense. Am J Emerg Med, 2018. 36 (7): p. 1307-1309.

[13] Hassen, G. W., et al., K2 types and their contents: are product disclosures true? Am J Emerg Med, 2015. 33 (6): p. 845-6.

[14] Hassen, G. W. and H. Kalantari, Synthetic drugs: time to ring the warning bell? Am J Emerg Med, 2013. 31 (12): p. 1714-5.

[15] Reyes, H. A., et al., Effect of Synthetic Cannabinoids in Older Adults. J Am Geriatr Soc, 2017. 65 (9): p. 2115-2117.

[16] Roy, A. A., et al., The rise in K2 use with varying clinical symptoms and the potential for ED crowding. Am J Emerg Med, 2015. 33 (4): p. 582.

[17] Sweeney, B., et al., Hyperthermia and severe rhabdomyolysis from synthetic cannabinoids. Am J Emerg Med, 2016. 34 (1): p. $121 \mathrm{e} 1-2$.

[18] Von Der Haar, J., et al., Synthetic Cannabinoids and Their Effects on the Cardiovascular System. J Emerg Med, 2016. 50 (2): p. 258-62.

[19] https://www.nytimes.com/2016/07/15/nyregion/k2-overdosespike-in-new-york-at-least-130-cases-this-week-alone.html.

[20] https://www.nytimes.com/2016/07/13/nyregion/k2-syntheticmarijuana-overdose-inbrooklyn.html ?action $=$ click \& contentCollection $=N . Y . \% 20 \% 2 F$ $\%$. 
[21] https://consumer.healthday.com/public-health-information30/poisons-health-news-537/synthetic-pot-laced-with-ratpoison-lands-people-in-the-er-749632.html.

[22] Fantegrossi, W. E., et al., Distinct pharmacology and metabolism of K2 synthetic cannabinoids compared to Delta (9) -THC: mechanism underlying greater toxicity? Life Sci, 2014. 97 (1): p. 45-54.

[23] Basavarajappa, B. S. and S. Subbanna, Potential Mechanisms Underlying the Deleterious Effects of Synthetic Cannabinoids Found in Spice/K2 Products. Brain Sci, 2019. 9 (1).

[24] Solimini, R., et al., Hepatotoxicity associated to synthetic cannabinoids use. Eur Rev Med Pharmacol Sci, 2017. 21 (1 Suppl): p. 1-6.
[25] Varga, Z. V., et al., Drug-induced mitochondrial dysfunction and cardiotoxicity. Am J Physiol Heart Circ Physiol, 2015. 309 (9): p. H1453-67.

[26] Pines, J. M., Emergency department crowding in California: a silent killer? Ann Emerg Med, 2013. 61 (6): p. 612-4.

[27] Hassen, G. W., F. Ghobadi, and H. Kalantari, Synthetic drugs: a new trend and the hidden danger. Am J Emerg Med, 2013. 31 (9): p. 1413-5.

[28] https://www.nytimes.com/2016/07/14/nyregion/k2-overdosesbrooklyn-police-raids.html?_r=0.

[29] http://nymag.com/intelligencer/2016/07/after-k2-overdoseraids-and-protests.html. 